\title{
Large Element Count Flag
}

National Cancer Institute

\section{Source}

National Cancer Institute. Large Element Count Flag. NCI Thesaurus. Code C42691.

A flag indicating whether the protection group has a large number of protection elements. 